\title{
An Artificial Neural Networks Approach to Estimate Occupational Accident: A National Perspective for Turkey
}

\author{
Hüseyin Ceylan \\ Kırıkkale Vocational School, Kırıkkale University, 71451 Kırıkkale, Turkey \\ Correspondence should be addressed to Hüseyin Ceylan; husceylan@hotmail.com
}

Received 30 October 2014; Accepted 1 December 2014; Published 28 December 2014

Academic Editor: Leonid Shaikhet

Copyright (C) 2014 Hüseyin Ceylan. This is an open access article distributed under the Creative Commons Attribution License, which permits unrestricted use, distribution, and reproduction in any medium, provided the original work is properly cited.

\begin{abstract}
Occupational accident estimation models were developed by using artificial neural networks (ANNs) for Turkey. Using these models the number of occupational accidents and death and permanent incapacity numbers resulting from occupational accidents were estimated for Turkey until the year of 2025 by the three different scenarios. In the development of the models, insured workers, workplace, occupational accident, death, and permanent incapacity values were used as model parameters with data between 1970 and 2012. 2-5-1 neural network architecture was selected as the best network architecture. Sigmoid was used in hidden layers and linear function was used at output layer. The feed forward back propagation algorithm was used to train the network. In order to obtain a useful model, the network was trained between 1970 and 1999 to estimate the values of 2000 to 2012 . The result was compared with the real values and it was seen that it is applicable for this aim. The performances of all developed models were evaluated using mean absolute percent errors (MAPE), mean absolute errors (MAE), and root mean square errors (RMSE).
\end{abstract}

\section{Introduction}

As the numbers of deaths, injuries, and incapacities to work, occurring as a result of occupational accidents, bring out material-moral losses for Turkey, they also form an occupational safety issue for the workers. Nowadays as the economy grows rapidly and concordantly the number of workplaces and workers also increases, occupational safety gains vital importance. Solely in 2012, 74871 occupational accidents happened in Turkey and as a result of these accidents 744 people died and 2036 people had permanent disability and incapacity to work [1]. When a year is approved to have 300 workdays, in Turkey approximately 250 occupational accidents happen per day, 7 workers have incapacity to work, and again 3 workers die per day. These values are official results obtained by the Social Security Institution (SSI). Accordingly, they are values informed solely to SSI, recorded officially. As it is considered that not all of the accidents are recorded officially and some of the workers are uninsured, the dimension of the issue will grow up more.

Being parallel to the developing technology, production systems become more complex. As a result of this, in order to avoid occupational accidents, new precautions are required to be developed. In Turkey, “The National Occupational Health and Safety Council" that is established within the Ministry of Labor and Social Security is responsible for determination of requirements, priorities, policies, and strategies for occupational health and safety. Within this framework, predictions of prospective accidents are required in order to determine planning and policies for prevention of occupational accidents, formation of more productive and secure working conditions. The reliability of these predictions depends on reliability of data of parameters affecting the accidents and the statistical analysis method that is applied.

The economy entered a major growth trend in Turkey in the last decade. At the moment, being the world's 16th largest economy, Turkey aims to be one of the 10 greatest economies in the world. Parallel to the growth of the economy, significant increase occurred in the number of both workplaces and employees; as a result of this the employees affected from occupational accidents have increased at significant rate. As a result of occupational accidents occurring, every day several employees are dying or are being seriously injured, but when these events are assessed separately, it is seen that this problem's impotence cannot be understood by either society or government as enough. However, on average 
1500 employees are dying and 2100 employees are having permanent incapacity resulting from occupational accidents per year in Turkey. Moreover, this figure tends to increase in line with growth in the economy. In this study the occupational accidents as an important problem for Turkey tend to increase in line with growth in the economy and the number of events of deaths and injuries resulting from them was tried to estimate till the year of 2025 . With this way, we have tried to reveal the true extent of the problem and also we have attempted to draw a perspective regarding the safety issue to decision makers.

By using separate approaches and analyses, many accident prediction models have been developed. In prediction studies, besides regression analyses (RA) [2, 3] and genetic algorithms (GA) [4, 5], artificial neural networks (ANNs) $[4,6-12]$ are also used. Mussone et al. used ANN techniques in order to analyze the accidents caused by vehicles in Milan, Italy, and develop an accident model [13]. Abdelwahab and Abdel-Aty used ANN techniques in order to predict violence of injury for drivers in accidents happening at signalized intersections [14]. Similarly, Delen et al. tried to model nonlinear relation between factors related to the collision and violence of injury by ANN method [15]. Akgüngör and Doğan used ANN-based expert system for accidents resulting from the collision of two vehicles and determined that right of way, accident location, and use of alcohol were prevalent variables in occurrence of an accident [16]. Akgüngör and Doğan, by applying ANN and nonlinear regression techniques, predicted number of accidents, injuries, and deaths for Turkey and by using diverse error criteria compared models obtained by both of the methods. As a result, it is stated that predictions of ANN model are more successful compared to nonlinear regression model [16]. Doğan and Akgüngör developed models predicting number of traffic accidents, injuries, and deaths for Kirlkkale by using ANN [17]. Doğan compared artificial intelligence techniques such as ANN and GA for Turkey and selected metropolis and stated that models by artificial intelligence had the greater performance [18]. Akgüngör and Doğan developed models predicting number of traffic accidents, injuries, and deaths as a result of these accidents for Istanbul by using ANN and GA methods [19].

In this study, occupational accident estimation models were developed by using ANNs for Turkey. Using these models the number of occupational accidents and death and permanent incapacity numbers resulting from occupational accidents were estimated for Turkey until the year 2025 by the three different scenarios. In the development of the models, insured worker, workplace, occupational accident, death, and permanent incapacity values were used as model parameters with data between 1970 and 2012. The result of model was compared to the real values and it is found that it is applicable for this aim.

\section{Artificial Neural Networks}

$\mathrm{ANN}$ is a data processing system resulting from mathematical modeling of learning process inspired by human. It is a structure which consists of simple processors trying to imitate the basic abilities of human brain's features like learning,

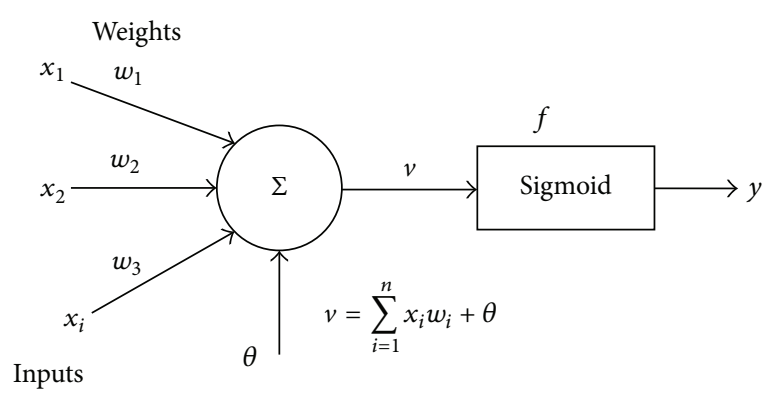

FIGURE 1: Basic artificial neural network cell: artificial neuron.

remembering, forming new knowledge, making generalization, and exploring.

The basic processor forming ANN is artificial neuron (Figure 1). In an artificial neuron inputs $\left(x_{i}\right)$, weights $\left(w_{i}\right)$, summing function $(\Sigma)$, activation function $(f)$, and output $(y)$ are present.

As we analyze basic ANN cell seen in Figure 1, $x_{1}, x_{2}, \ldots, x_{i}$ values are cell inputs. The obtained inputs are multiples by certain weights and by summing with threshold values varying among -1 and +1 net input is formed. By making transaction at activation function over the net input, cell output is tried to be transformed into the desired intervals. By comparing this output value by the output known for the system, an error ratio is found. In accordance with this error ratio, artificial neural network cell updates new weight values of the inputs. Therefore, a loop is made to gather more accurate results. The learning of the network occurs by the updating of these weights:

$$
y=f\left(\sum_{i=1}^{n} w_{i} x_{i}+\theta\right) .
$$

Activation function is used for transforming the output into the desired intervals. There are many activation functions in which ANN cells are used. Because tangenthyperbolic, sigmoid, and linear functions give better results, they are the activation functions mostly preferred. Activation function can be both linear and nonlinear. It is a desirable case to have continuous and differentiable activation function $[20,21]$.

2.1. Tangent-Hyperbolic Function. This function gets value among -1 and 1 which is nonlinear, and it is applied to reach to a result within ANN. Tangent-hyperbolic function uses the equation

$$
f(v)=\frac{e^{v}+e^{-v}}{e^{v}-e^{-v}}
$$

2.2. Sigmoid Function. This is a differentiable and nonlinear function which gets value among 0 and 1 and is mostly used to make generalizations within ANN. Sigmoid function uses the equation

$$
f(v)=\frac{1}{1+e^{-v}} .
$$




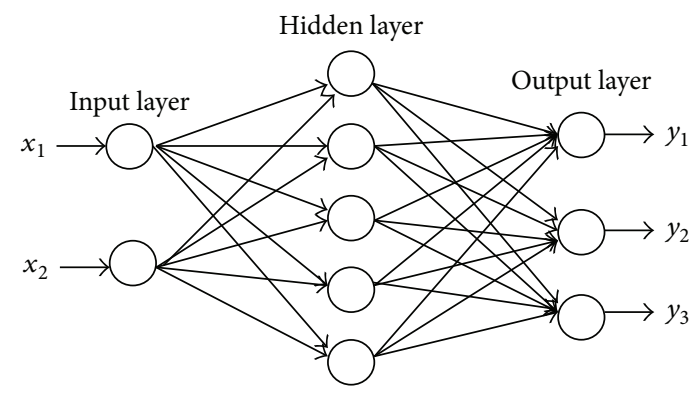

Figure 2: Multilayer ANN structure.

2.3. Linear Function. This is a differentiable and linear function which gets value among 0 and 1 and is applied to reach to the result. Linear function uses the equation

$$
f(v)=\alpha * v .
$$

Artificial neural networks are formed by connecting artificial neurons with each other by several architectures. In Figure 2, we see an ANN model in which 10 artificial neurons are bound to each other forwarding with multilayers. In its architecture 2-5-3 network structures are used. In the architecture of ANN, there is an input layer where inputs are injected to the network and a hidden layer where information from input layer is processed and transmitted to output layer. In this figure, $X$ values show the input; $Y$ values show the output values. As it is seen in this figure, the neurons forming ANN can be arranged in a desired number. However, in order to find the accurate result, finding the appropriate architecture is highly crucial. Because the number of neurons is definite at input and output layers, the issue waiting for a result is the number of hidden layers and number of neurons at each hidden layer. There is no certain method in the literature about this issue. These attributes changing in accordance with the issue are found by trial-and-error method.

Although ANNs indicate diverse characteristics in accordance with the diversities in the model, they have some common features. The first of these features is the capability of working in parallel. In other words, ANNs are made up of many neurons; these neurons work simultaneously and they do many complicated operations concurrently. The second feature is that network function can be nonlinear. In this respect the network can also give accurate results for nonlinear data given as an input to the system mathematically. The third feature is talent of generalization. In other words, the network structure finds the most appropriate weight values $\left(w_{i}\right)$ during the training and forms several responses for new inputs by using these weight values. The fourth feature is that ANNs designed in digital media can be authenticated as hardware.

ANNs are applied in the areas of prediction, classification, modeling, control systems, and optimization. They are frequently applied in aviation, flight simulation, and automatic pilot applications; in security systems, fingerprint identification, face matching, and retina identification; in automotive sector, automatic road identification and driving analyses; in medical sector; EEG (electroencephalography),
ECG (electrocardiography), and MR (magnetic resonance) systems; in defense industry, target selection, radar systems, and signal and image processing; in linguistics, word identification.

\section{ANN Prediction Model for Occupational Accidents}

In general, occupational accidents have not one reason, but they occur as a result of interaction of many factors with each other. Many factors such as workers being tired and careless, handling excess load, inadequate safety precautions at the stalls, employing incompetent workers, use of inadequate and improper machine and protective equipment, irregular and scattered office, not making regular maintenance of the apparatus, not putting the required warning signs and statements, and lack of communication cause the accidents. However, the accumulation of all of the parameters having impact on the accident on a single model is usually not possible. Additionally, it is not applicable regarding the usability of the model in practical way; therefore, the model to be developed is desired to be simple and reliable. Because of this, in accident prediction models developed for Turkey, as a model parameter, numbers of workplaces and insured workers considered to be directly related to the accidents are applied. Easy access to data of these two parameters and the model to be developed should not be a model for a certain region, but rather a model covering whole of the country is another reason for preference. The data used in this study and given in Table 1 regarding numbers of workplaces, compulsory insured workers, occupational accidents, and death and permanent incapacity numbers resulting from occupational accidents covering the years 1970-2012 are obtained by statistics of Social Security Institution (SSI).

While predicting accident model by ANN, many different network architectures are applied and it is seen that 2-5-1 network architecture given in Figure 3 is the most appropriate for this study. As activation function, at the first layer "tangent sigmoid" and at the second layer "linear" functions are used. As network type feed forwarding back propagation algorithm, as learning function "trainlm," performance functions "mean absolute percent errors (MAPE)," "mean absolute errors (MAE)," and "root mean square errors (RMSE)" are preferred. As seen in the figure, as input parameter, only number of workplaces and insured workers is used; number of accidents and death and permanent incapacity numbers resulting from occupational accidents are tried to be predicted.

\section{Results of Application of ANN Prediction Models for Turkey}

For the prediction of values of occupational accident and death and permanent incapacity numbers resulting from occupational accidents, three different ANN models are formed.

Firstly, to search for the efficiency for the models, by training our network by data between the years 1970 and 
TABLE 1: The annual distribution of the occupational accident data in Turkey between the years 1970 and 2012.

\begin{tabular}{|c|c|c|c|c|c|}
\hline Year & $\begin{array}{l}\text { Number of insured } \\
\text { workers }\end{array}$ & $\begin{array}{l}\text { Number of } \\
\text { workplaces }\end{array}$ & $\begin{array}{l}\text { Number of } \\
\text { occupational } \\
\text { accidents }\end{array}$ & $\begin{array}{c}\text { Deaths resulting from } \\
\text { occupational } \\
\text { accidents }\end{array}$ & $\begin{array}{c}\text { Permanent } \\
\text { incapacities resulting } \\
\text { from occupational } \\
\text { accidents }\end{array}$ \\
\hline 1970 & 1.313 .500 & 109.391 & 144.483 & 679 & 2480 \\
\hline 1971 & 1.404 .816 & 154.812 & 148.822 & 583 & 2574 \\
\hline 1972 & 1.525 .012 & 174.344 & 160.585 & 682 & 2359 \\
\hline 1973 & 1.649 .079 & 184.427 & 176.993 & 822 & 2372 \\
\hline 1974 & 1.799 .998 & 195.929 & 180.375 & 983 & 2643 \\
\hline 1975 & 1.823 .338 & 205.441 & 182.601 & 855 & 2560 \\
\hline 1976 & 2.017 .875 & 216.941 & 196.341 & 947 & 2659 \\
\hline 1977 & 2.191 .251 & 229.198 & 199.961 & 1.135 & 3123 \\
\hline 1978 & 2.206 .056 & 231.130 & 193.998 & 975 & 2841 \\
\hline 1979 & 2.152 .411 & 239.225 & 186.089 & 1.050 & 2053 \\
\hline 1980 & 2.204 .807 & 241.580 & 159.600 & 1.014 & 2406 \\
\hline 1981 & 2.228 .439 & 259.589 & 165.101 & 938 & 2300 \\
\hline 1982 & 2.264 .788 & 273.226 & 147.118 & 831 & 1881 \\
\hline 1983 & 2.327 .245 & 281.627 & 145.296 & 1.070 & 2592 \\
\hline 1984 & 2.439 .016 & 294.284 & 152.650 & 885 & 2453 \\
\hline 1985 & 2.607 .865 & 326.996 & 148.027 & 877 & 2549 \\
\hline 1986 & 2.815 .230 & 365.514 & 150.821 & 1.108 & 2282 \\
\hline 1987 & 2.878 .925 & 387.452 & 158.836 & 838 & 2483 \\
\hline 1988 & 3.140 .071 & 451.662 & 171.769 & 1.163 & 2170 \\
\hline 1989 & 3.271 .013 & 474.318 & 159.463 & 1.150 & 2394 \\
\hline 1990 & 3.446 .502 & 514.390 & 155.857 & 1.292 & 2778 \\
\hline 1991 & 3.598 .315 & 536.098 & 130.278 & 1.189 & 3334 \\
\hline 1992 & 3.796 .702 & 559.184 & 139.464 & 1.583 & 3044 \\
\hline 1993 & 3.976 .202 & 610.129 & 109.563 & 1.064 & 3522 \\
\hline 1994 & 4.202 .616 & 691.023 & 92.087 & 1.034 & 2791 \\
\hline 1995 & 4.410 .744 & 724.427 & 87.960 & 798 & 2188 \\
\hline 1996 & 4.624 .330 & 759.342 & 86.807 & 1.296 & 2249 \\
\hline 1997 & 4.830 .056 & 781.911 & 98.318 & 1.282 & 3445 \\
\hline 1998 & 5.299 .533 & 813.010 & 91.895 & 1.094 & 2677 \\
\hline 1999 & 5.005 .403 & 769.674 & 77.955 & 1.165 & 2697 \\
\hline 2000 & 5.254 .125 & 753.275 & 74.847 & 731 & 1493 \\
\hline 2001 & 4.886 .881 & 723.503 & 72.367 & 1.002 & 1866 \\
\hline 2002 & 5.223 .283 & 727.409 & 72.344 & 872 & 1820 \\
\hline 2003 & 5.615 .238 & 777.177 & 76.668 & 810 & 1451 \\
\hline 2004 & 6.181 .251 & 850.928 & 83.830 & 841 & 1421 \\
\hline 2005 & 6.918 .605 & 944.984 & 73.923 & 1.072 & 1374 \\
\hline 2006 & 7.818 .642 & 1.036 .328 & 79.027 & 1.592 & 1953 \\
\hline 2007 & 8.505 .390 & 1.116 .638 & 80.602 & 1.043 & 1550 \\
\hline 2008 & 8.802 .989 & 1.170 .248 & 72.963 & 865 & 1452 \\
\hline 2009 & 9.030 .202 & 1.216 .308 & 64.316 & 1.171 & 1668 \\
\hline 2010 & 10.030 .810 & 1.325 .749 & 62.903 & 1.444 & 1976 \\
\hline 2011 & 11.030 .939 & 1.435 .879 & 69.277 & 1700 & 2093 \\
\hline 2012 & 11.939 .620 & 1.538 .006 & 74.871 & 744 & 2036 \\
\hline
\end{tabular}




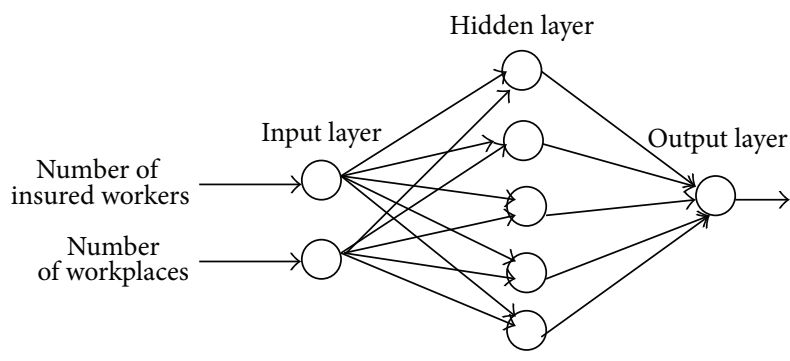

Figure 3: Network architecture of occupational accident model for Turkey.

TABLE 2: Error values for accident models.

\begin{tabular}{lccc}
\hline Error code & $\begin{array}{c}\text { Prediction of } \\
\text { occupational } \\
\text { accident }\end{array}$ & $\begin{array}{c}\text { Prediction of } \\
\text { death }\end{array}$ & $\begin{array}{c}\text { Prediction of } \\
\text { permanent } \\
\text { incapacity }\end{array}$ \\
\hline MAPE & 3,24 & 6,21 & 7,55 \\
RMSE & 2873 & 148 & 207 \\
MAE & 2169 & 65 & 132 \\
\hline
\end{tabular}

1999, predictions of numbers of occupational accidents and death and permanent incapacity numbers resulting from occupational accidents between the years 2000 and 2012 are done and the results are compared with the real values.

In Figure 4, the values of number of occupational accidents predicted by ANN model and values of real occupational accidents between the years 2000 and 2012 for Turkey are given.

In Figure 5, the values of death numbers resulting from occupational accidents predicted by ANN model and values of real death numbers resulting from occupational accidents between the years 2000 and 2012 for Turkey are given.

In Figure 6, the values of permanent incapacity numbers resulting from occupational accidents predicted by ANN model and values of real permanent incapacity numbers resulting from occupational accidents between the years 2000 and 2012 for Turkey are given.

The performances of all developed models were evaluated by the use of mean absolute percent errors (MAPE), mean absolute errors (MAE), and root mean square errors (RMSE) and they are given in Table 2:

$$
\begin{aligned}
\text { OMYH } & =\frac{1}{n} \sum\left[\left|\frac{o_{i}-t_{i}}{o_{i}}\right| * 100\right], \\
\text { OKHK } & =\sqrt{\left[\frac{1}{n} \sum\left[o_{i}-t_{i}\right]^{2}\right]}, \\
\text { OMH } & =\frac{1}{n} \sum\left(\left|o_{i}-t_{i}\right|\right) .
\end{aligned}
$$

As the error values are analyzed, it is seen that ANN models are appropriate.

\section{Accident Scenarios for Turkey}

It is approved that predictions until the year 2025 by ANN models of which the error values are given in Table 2 will

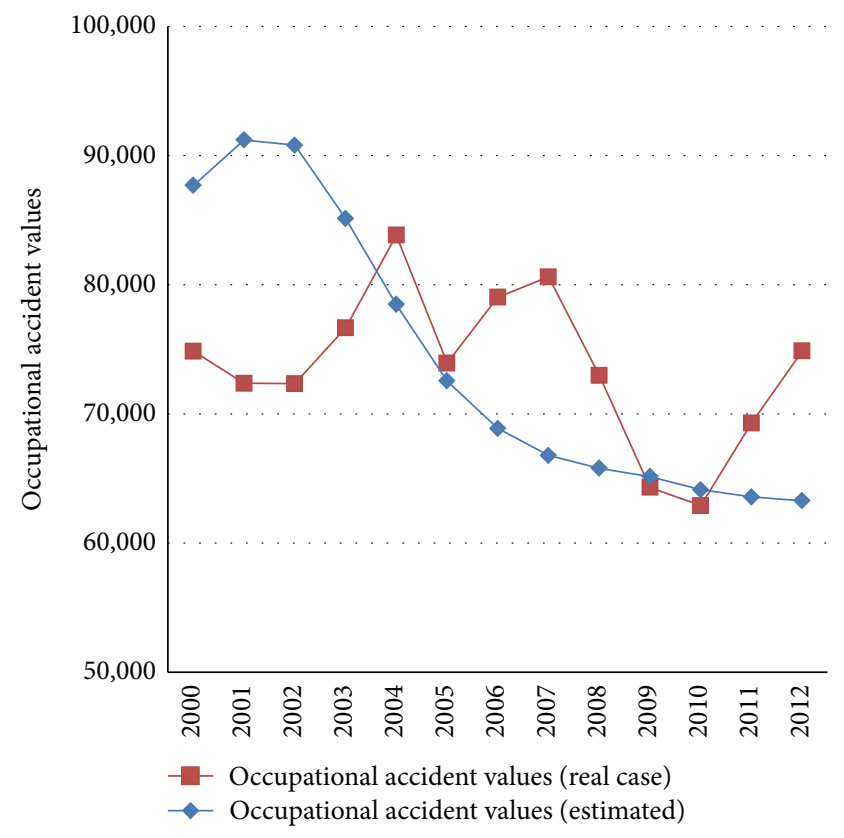

FIGURE 4: Real and estimated occupational accident values produced by ANN model for Turkey.

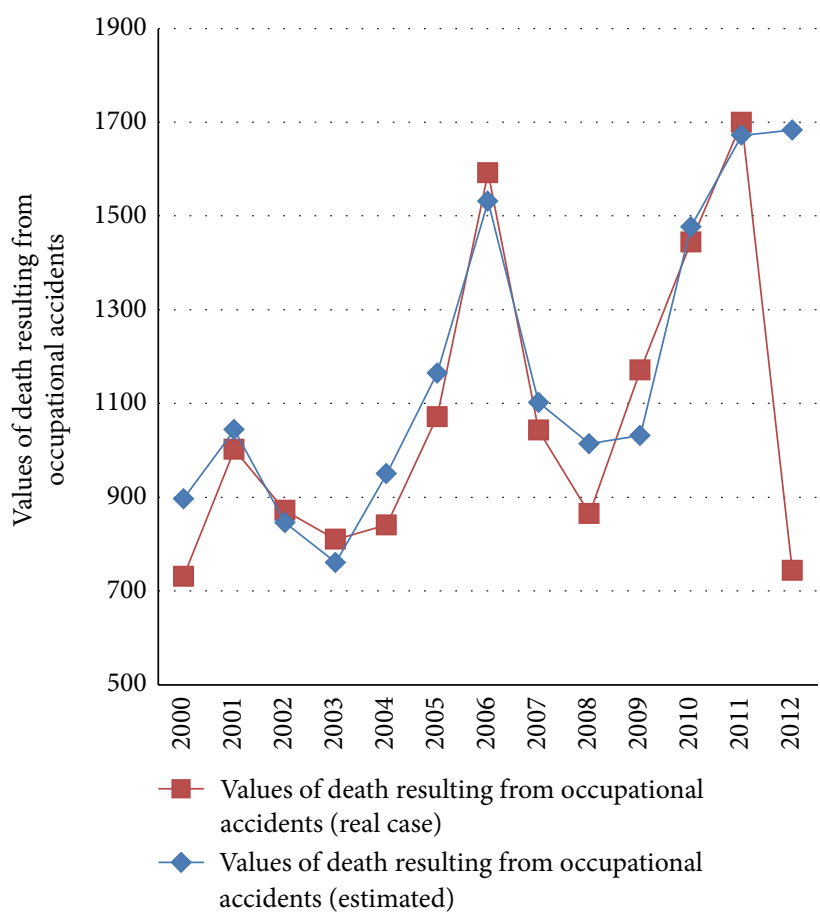

FIGURE 5: Real and estimated death values produced by ANN model for Turkey.

be applied and predictions are made by 3 diverse scenarios. In scenario 1 , there is $50 \%$ of the rate of increase between the years 1970 and 2012 for number of insured workers and workplaces, in scenario 2 there is $100 \%$ of the rate of increase, and in Scenario $3150 \%$ is taken. 


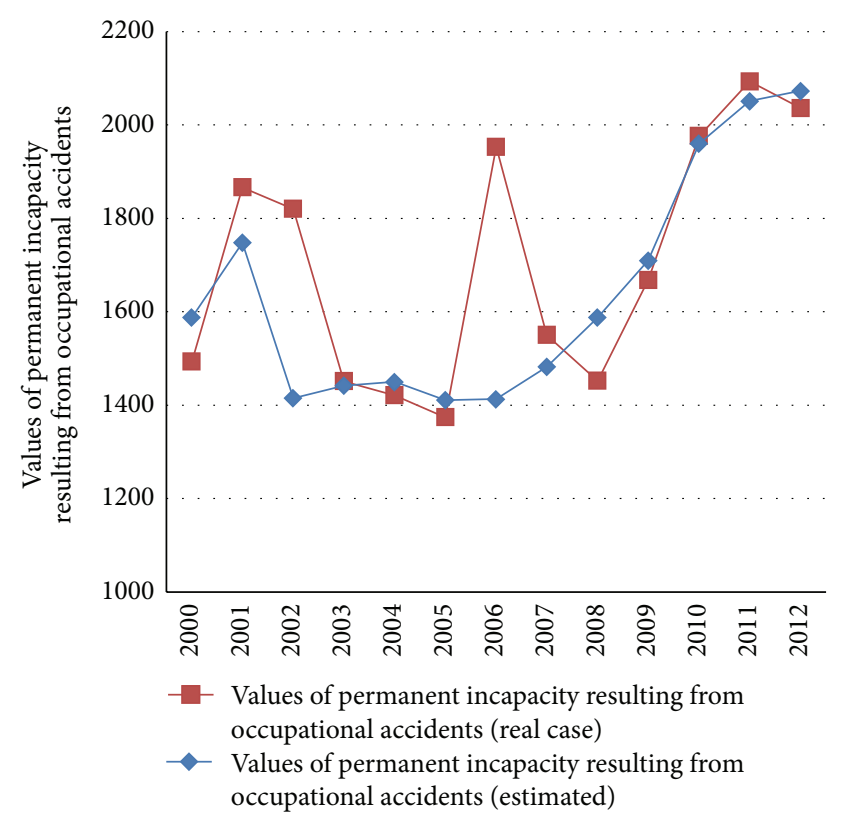

FIGURE 6: Real and estimated permanent incapacity values produced by ANN model for Turkey.

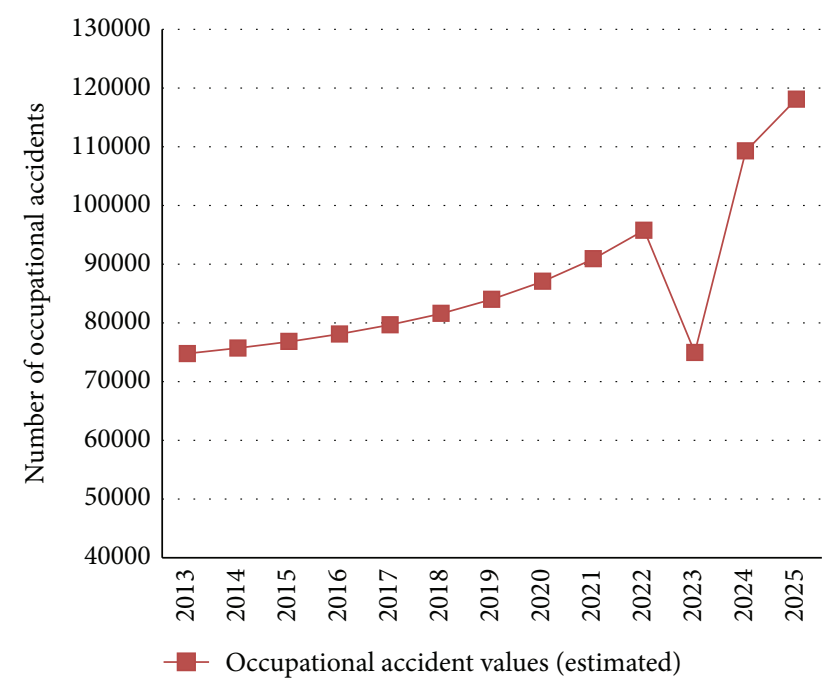

FIGURE 7: ANN predictions about the number of occupational accidents within the first scenario recommended for Turkey.

The foreseen ratios are determined to be in scenario 1 $2.5 \%$ for the insured workers and 3.3\% for the workplaces, in scenario $25.15 \%$ for the insured workers and $6.59 \%$ for the workplaces, and in scenario $37.73 \%$ for the insured workers and $9.89 \%$ for the workplaces.

In the study of prediction made in accordance with the 1st scenario by ANN model, the results shown in Table 3 are obtained. According to this table, it is seen that in Turkey there will be increase in the amount of occupational accidents, death as a result of occupational accident, and permanent incapacity as a result of occupational accident in the coming future.

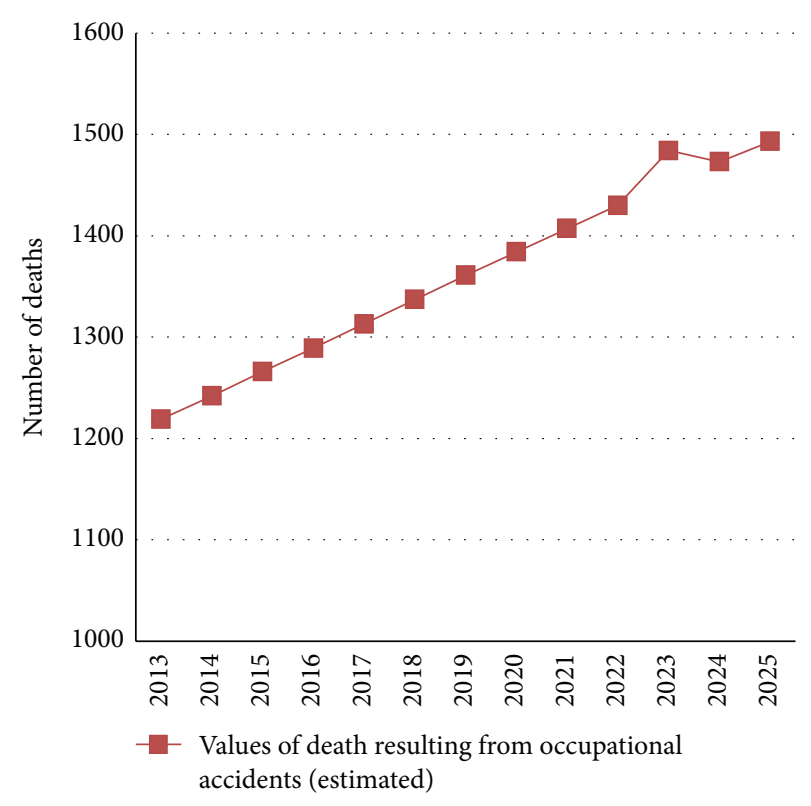

FIGURE 8: ANN predictions about the number of deaths resulting from occupational accidents within the first scenario recommended for Turkey.

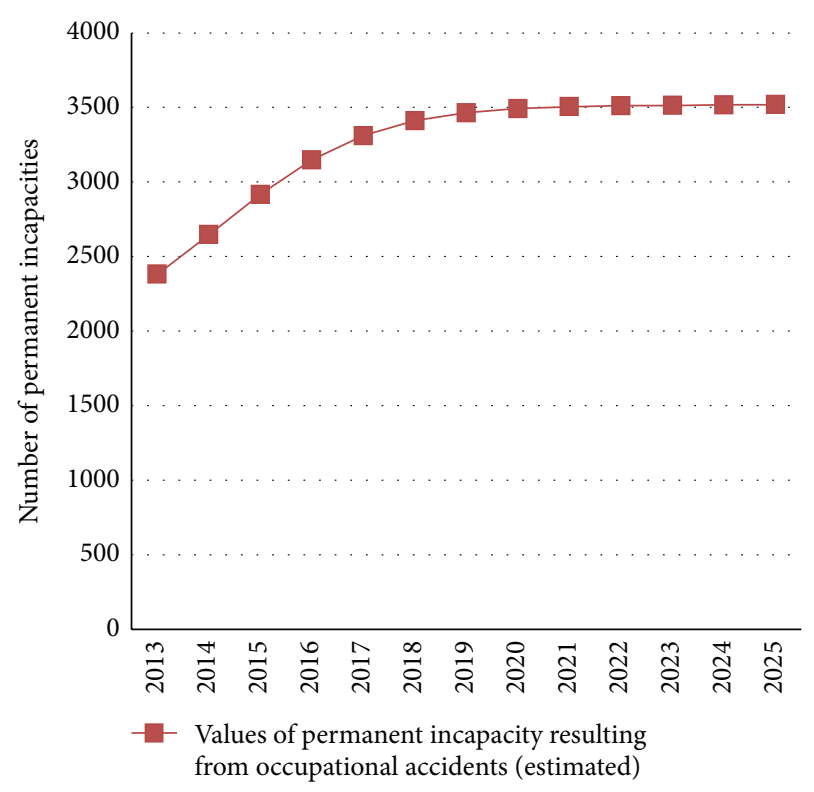

FIGURE 9: ANN predictions about the number of permanent incapacities resulting from occupational accidents within the first scenario recommended for Turkey.

As Figure 7 is analyzed, it is seen that the values of the estimated occupational accidents have the tendency to increase. It is predicted that the number of occupational accidents will reach to 118077 in 2025, with an increase of $57 \%$ compared to the year 2012. As Figure 8 is analyzed, the number of deaths as a result of occupational accident is estimated to reach to 1493 in 2025 with an increase of $101 \%$ as compared to the year 2012. As Figure 9 is analyzed, 
TABLE 3: Predictions about the number of occupational accidents, deaths, and permanent incapacities produced by ANN models in accordance with the first scenario for Turkey.

\begin{tabular}{lccccc}
\hline Year & $\begin{array}{c}\text { Number of insured } \\
\text { workers }\end{array}$ & $\begin{array}{c}\text { Number of } \\
\text { workplaces }\end{array}$ & $\begin{array}{c}\text { Number of } \\
\text { occupational } \\
\text { accidents }\end{array}$ & $\begin{array}{c}\text { Deaths resulting from } \\
\text { occupational } \\
\text { accidents }\end{array}$ & $\begin{array}{c}\text { Permanent } \\
\text { incapacities resulting } \\
\text { from occupational } \\
\text { accidents }\end{array}$ \\
\hline 2013 & 12.238 .111 & 1.588 .760 & 74741 & 1219 & 2381 \\
2014 & 12.544 .063 & 1.641 .189 & 75682 & 1242 & 2647 \\
2015 & 12.857 .665 & 1.695 .349 & 76779 & 1266 & 2917 \\
2016 & 13.179 .106 & 1.751 .295 & 78081 & 1289 & 3148 \\
2017 & 13.508 .584 & 1.809 .088 & 79652 & 1313 & 3311 \\
2018 & 13.846 .299 & 1.868 .788 & 81585 & 1337 & 3411 \\
2019 & 14.192 .456 & 1.930 .458 & 83997 & 1384 & 3464 \\
2020 & 14.547 .268 & 1.994 .163 & 87038 & 1407 & 3492 \\
2021 & 14.910 .949 & 2.059 .970 & 90886 & 1430 & 3505 \\
2022 & 15.283 .723 & 2.127 .949 & 95739 & 1484 & 3512 \\
2023 & 15.665 .816 & 2.198 .171 & 74925 & 1473 \\
2024 & 16.057 .462 & 2.270 .711 & 109224 & 1493 & 3513 \\
2025 & 16.458 .898 & 2.345 .645 & 118077 & 3519 \\
\hline
\end{tabular}

TABLE 4: Predictions about the number of occupational accidents, deaths, and permanent incapacities produced by ANN models in accordance with the second scenario for Turkey.

\begin{tabular}{lccccc}
\hline Year & $\begin{array}{c}\text { Number of insured } \\
\text { workers }\end{array}$ & $\begin{array}{c}\text { Number of } \\
\text { workplaces }\end{array}$ & $\begin{array}{c}\text { Number of } \\
\text { occupational } \\
\text { accidents }\end{array}$ & $\begin{array}{c}\text { Deaths resulting from } \\
\text { occupational } \\
\text { accidents }\end{array}$ & $\begin{array}{c}\text { Permanent } \\
\text { incapacities resulting } \\
\text { from occupational } \\
\text { accidents }\end{array}$ \\
\hline 2013 & 12554510 & 1639361 & 73189 & 780 & 2466 \\
2014 & 13201068 & 1747394 & 73483 & 804 & 2789 \\
2015 & 13880923 & 1862548 & 73893 & 880 & 2950 \\
2016 & 14595790 & 1985290 & 74476 & 958 & 3017 \\
2017 & 15347473 & 2116120 & 75319 & 998 & 3043 \\
2018 & 16137868 & 2255573 & 76548 & 1133 & 3051 \\
2019 & 16968969 & 2404215 & 78350 & 1318 & 3053 \\
2020 & 17842870 & 2562653 & 80982 & 1563 & 3051 \\
2021 & 18761778 & 2731531 & 84762 & 1586 & 3049 \\
2022 & 19728010 & 2911539 & 89971 & 1606 & 3046 \\
2023 & 20744002 & 3103410 & 96663 & 1640 & 3044 \\
2024 & 21812318 & 3307924 & 104429 & 1667 & 3042 \\
2025 & 22935653 & 3525917 & 112403 & 3041 \\
\hline
\end{tabular}

the number of permanent incapacities due to occupational accident is estimated to reach to 3519 in 2025 with an increase of $72 \%$ as compared to the year 2012 .

In the study of prediction made in accordance with the 2nd scenario by ANN model, the results shown in Table 4 are obtained. According to this table, it is seen that in Turkey there will be increase in the amount of occupational accidents, death as a result of occupational accidents, and permanent incapacity as a result of occupational accidents in the coming future.

As Figure 10 is analyzed, it is seen that the values of the estimated occupational accidents have the tendency to increase. It is predicted that the number of occupational accidents will reach to 112403 in 2025 , with an increase of $50 \%$ compared to the year 2012. As Figure 11 is analyzed, the number of deaths as a result of occupational accidents is estimated to reach to 1667 in 2025 with an increase of $124 \%$ as compared to the year 2012. As Figure 12 is analyzed, the number of permanent incapacities due to occupational accidents is estimated to reach to 3041 in 2025 with an increase of $49 \%$ as compared to the year 2012 .

In the study of prediction made in accordance with the 3rd scenario by ANN model, the results shown in Table 5 are obtained. According to this table, it is seen that in 
TABLE 5: Predictions about the number of occupational accidents, deaths, and permanent incapacities produced by ANN models in accordance with the 3 rd scenario for Turkey.

\begin{tabular}{|c|c|c|c|c|c|}
\hline Year & $\begin{array}{l}\text { Number of insured } \\
\text { workers }\end{array}$ & $\begin{array}{l}\text { Number of } \\
\text { workplaces }\end{array}$ & $\begin{array}{l}\text { Number of } \\
\text { occupational } \\
\text { accidents }\end{array}$ & $\begin{array}{c}\text { Deaths resulting from } \\
\text { occupational } \\
\text { accidents }\end{array}$ & $\begin{array}{c}\text { Permanent } \\
\text { incapacities resulting } \\
\text { from occupational } \\
\text { accidents }\end{array}$ \\
\hline 2013 & 12862553 & 1690115 & 76746 & 689 & 2368 \\
\hline 2014 & 13856828 & 1857267 & 78482 & 914 & 2498 \\
\hline 2015 & 14927961 & 2040951 & 79863 & 985 & 2581 \\
\hline 2016 & 16081892 & 2242801 & 80768 & 1026 & 2659 \\
\hline 2017 & 17325022 & 2464614 & 82052 & 938 & 2755 \\
\hline 2018 & 18664247 & 2708364 & 84468 & 927 & 2884 \\
\hline 2019 & 20106993 & 2976221 & 86627 & 967 & 3047 \\
\hline 2020 & 21661263 & 3270570 & 93923 & 1078 & 3226 \\
\hline 2021 & 23335679 & 3594029 & 95974 & 1118 & 3380 \\
\hline 2022 & 25139527 & 3949479 & 102403 & 1290 & 3470 \\
\hline 2023 & 27082813 & 4340082 & 108429 & 1593 & 3505 \\
\hline 2024 & 29176314 & 4769316 & 110128 & 1448 & 3516 \\
\hline 2025 & 31431643 & 5241001 & 115938 & 1697 & 3518 \\
\hline
\end{tabular}

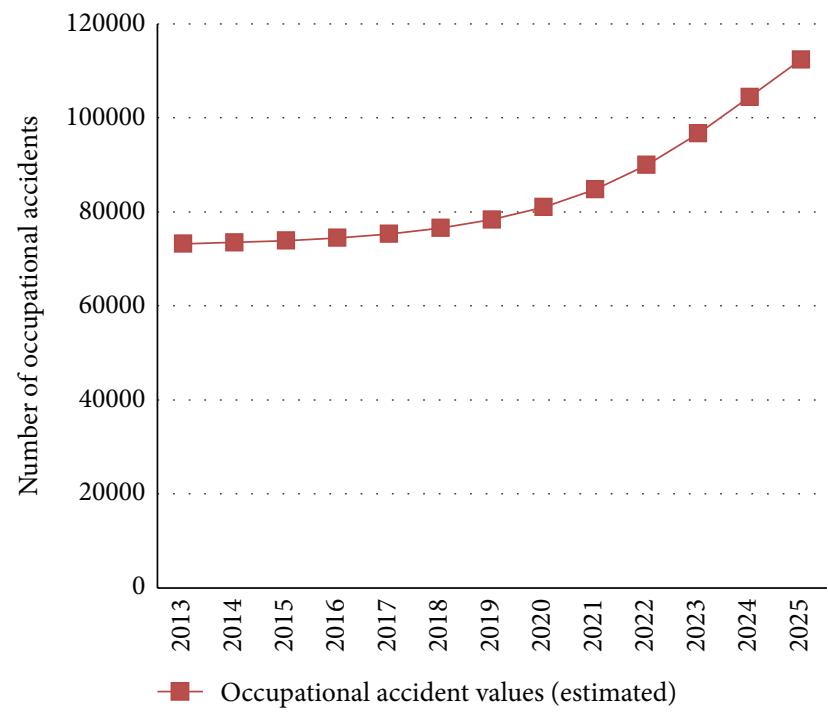

FIGURE 10: ANN predictions about the number of occupational accidents within the second scenario recommended for Turkey.

Turkey there will be increase in the amount of occupational accidents, death as a result of occupational accidents, and permanent incapacity as a result of occupational accidents in the coming future.

As Figure 13 is analyzed, it is seen that the values of the estimated occupational accidents have the tendency to increase. It is predicted that the number of occupational accidents will reach to 115938 in 2025, with an increase of 54\% compared to the year 2012. As Figure 14 is analyzed, the number of deaths as a result of occupational accidents is estimated to reach to 1967 in 2025 with an increase of $164 \%$ as compared to the year 2012. As Figure 15 is analyzed,

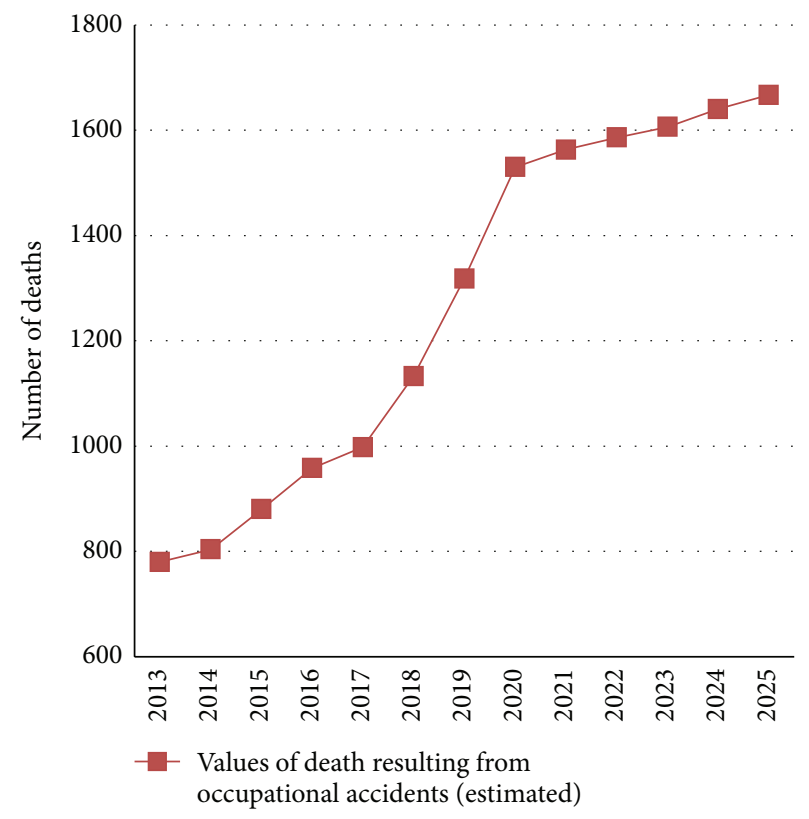

FIGURE 11: ANN predictions about the number of deaths resulting from occupational accidents within the second scenario recommended for Turkey.

the number of permanent incapacities due to occupational accidents is estimated to reach to 3518 in 2025 with an increase of $72 \%$ as compared to the year 2012 .

\section{Discussion of Results and Conclusions}

In this study, by using ANN, three diverse models are developed, predicting numbers of occupational accidents and death and permanent incapacity numbers resulting from 


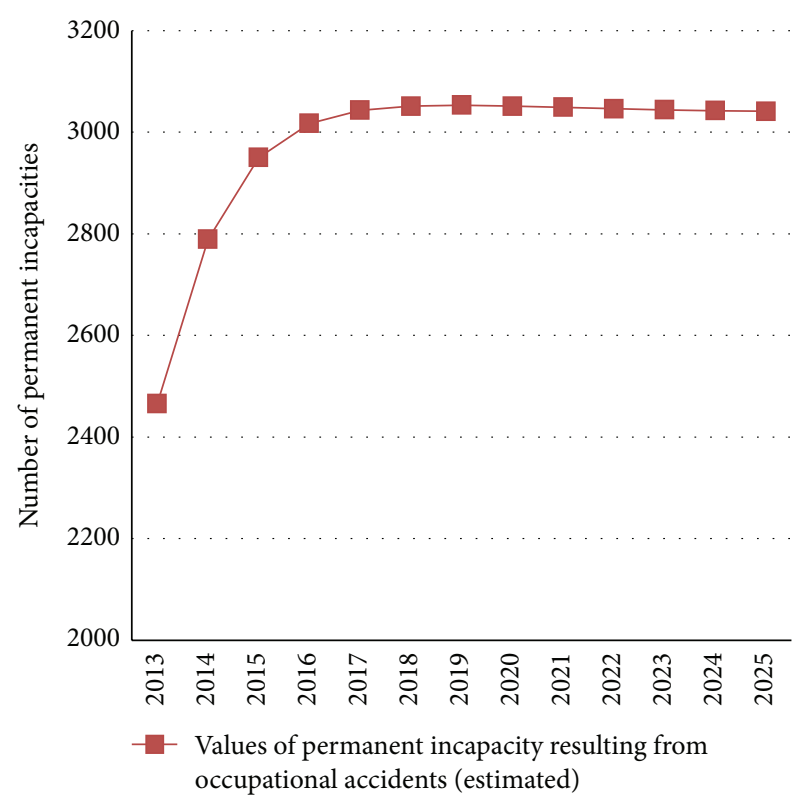

FIGURE 12: ANN predictions about the number of permanent incapacities resulting from occupational accidents within the second scenario recommended for Turkey.

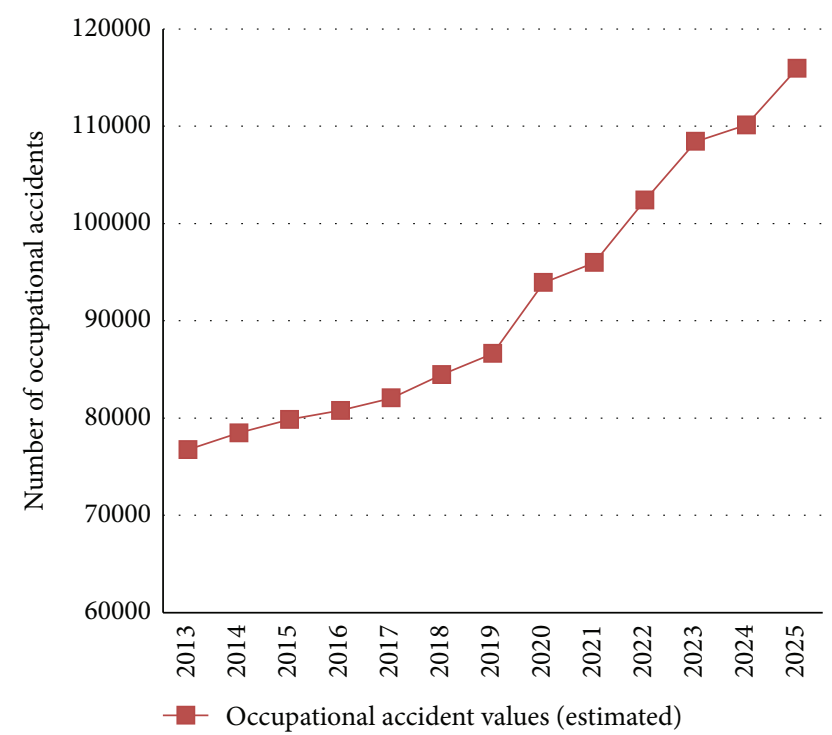

FIGURE 13: ANN predictions about the number of occupational accidents within the 3 rd scenario recommended for Turkey.

occupational accidents in Turkey. As developing each of the 3 accident models, numbers of insured workers, workplaces, occupational accidents, deaths, and permanent incapacities are used as the variables. In ANN accident models, diverse network architectures are applied and it is seen that 2-5-1 network architecture is the most appropriate one. As a result of performance analysis, it is seen that ANN can be applied as a good accident prediction model. In order to determine the model having the best performance, MAPE, MAE, and RMSE values are calculated in Table 2. As the scenarios foreseen

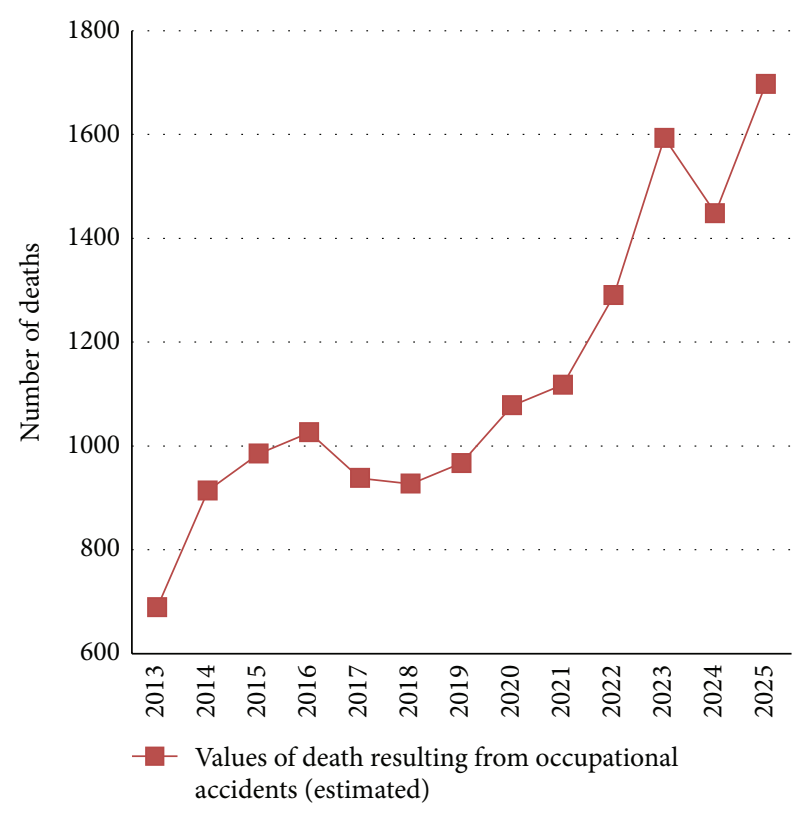

FIGURE 14: ANN predictions about the number of deaths resulting from occupational accidents within the 3rd scenario recommended for Turkey.

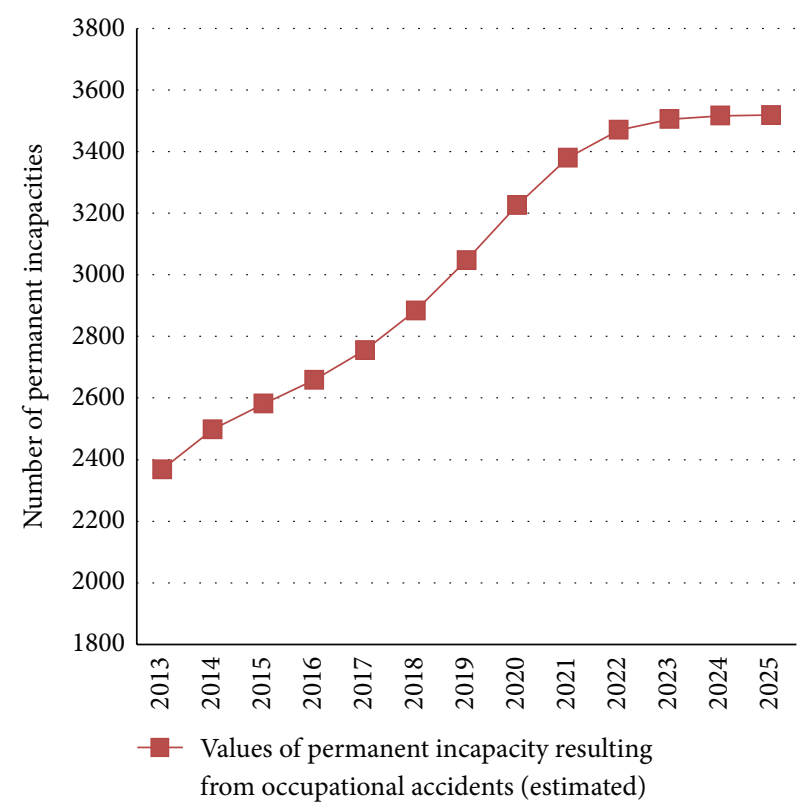

FIGURE 15: ANN predictions about the number of permanent incapacities resulting from occupational accidents within the 3rd scenario recommended for Turkey.

and predictions made for Turkey until the year 2025 are analyzed, it is seen in Tables 3, 4, and 5 that there will be an increase in the number of occupational accidents, resulting in death and permanent incapacity. As it is considered that numbers of insured workers and workplaces have the tendency to increase in Turkey, it is estimated that in the year 2025 the number of insured workers will be approximately 
20-25 million and workplaces will be approximately 4-5 million. The increase in numbers shows that occupational accidents resulting in death and permanent incapacity will also increase. In this case, in order to prevent occupational accidents and their results, occupational safety plan and policies should be revised and applied distinctly.

All the accidents occurring in Turkey have to be informed to Social Security Institution (SSI) in 3 workdays. In this study, official occupational accidents data belonging to SSI were used. Unfortunately underreporting is an important problem also for Turkey and the world. A big part of the occupational accidents occurring in Turkey cannot be recorded as well. However, most of the accidents resulted in death or permanent incapacity are recorded. Therefore, ANN estimation models which developed for death and permanent incapacity number produce more successful results than ANN estimation model which developed for number of occupational accidents.

\section{Conflict of Interests}

The author declares that there is no conflict of interests regarding the publication of this paper.

\section{References}

[1] SSI, Statistical Yearbook, SSI, Ankara, Turkey, 1970, 2012, http://www.sgk.gov.tr/wps/portal/tr/kurumsal/istatistikler.

[2] D. E. Goldberg, "The design of innovation lessons from genetic algorithms, lessons fort he real world," Technological Forecasting and Social Change, vol. 64, no. 1, pp. 7-12, 2000.

[3] E. Z. Şensoy, Nonlinear logistic regression and applications [M.S. thesis], Institute of Science and Technology, Marmara University, İstanbul, Turkey, 2009, (Turkish).

[4] http://www.figes.com.tr/matlab/uygulama-alanlari/index.php.

[5] Y. S. Murat and H. Ceylan, "Use of artificial neural networks for transport energy demand modeling," Energy Policy, vol. 34, no. 17, pp. 3165-3172, 2006.

[6] Y. C. Chio, "An ARIMA modeling: a case study of Turkey," Energy Policy, vol. 35, no. 2, pp. 1129-1146, 2007.

[7] Y.-C. Chiou, "An artificial neural network-based expert system for the appraisal of two-car crash accidents," Accident Analysis and Prevention, vol. 38, no. 4, pp. 777-785, 2006.

[8] A. P. Akgüngör and E. Doğan, "An artificial intelligent approach to traffic accident estimation: model development and application," Transport, vol. 24, no. 2, pp. 135-142, 2009.

[9] A. P. Akgüngör and E. ve Doğan, "Traffic accident prediction models developed using different methods and analysis," International Journal of Engineering Research and Development, vol. 2, no. 1, 2010 (Turkish).

[10] S. Önal, Forecasting of flow of Kizllırmak River by using neural networks method [M.S. thesis], Institute of Science and Technology, Süleyman Demirel University, Isparta, Turkey, 2009, (Turkish).

[11] D. Comaniciu and P. Meer, "Mean shift analysis and applications," in Proceedings of the IEEE International Conference on Computer Vision, pp. 1197-1203, 1999.

[12] Z. Şen, Artificial Neural Networks, Water Foundation Publications, Istanbul, Turkey, 2004, (Turkish).
[13] L. Mussone, A. Ferrari, and M. Oneta, "An analysis of urban collisions using an artificial intelligence model," Accident Analysis and Prevention, vol. 31, no. 6, pp. 705-718, 1999.

[14] H. T. Abdelwahab and M. A. Abdel-Aty, "Development of artificial neural network models to predict driver injury severity in traffic accidents at signalized intersections," Transportation Research Record, no. 1746, pp. 6-13, 2001.

[15] D. Delen, R. Sharda, and M. Bessonov, "Identifying significant predictors of injury severity in traffic accidents using a series of artificial neural networks," Accident Analysis and Prevention, vol. 38, no. 3, pp. 434-444, 2006.

[16] A. P. Akgüngör and E. Doğan, "Estimating road accidents of Turkey based on regression analysis and artificial neural network approach," Advances in Transportation Studies, no. 16, pp. 11-22, 2008.

[17] E. Doğan and A. P. Akgüngör, "Investigation of traffic accidents and results with artificial neural networks: Kirıkkale case," in Proceedings of the 8th Transportation Congress, pp. 279-287, İstanbul, Turkey, September/October 2009.

[18] E. Doğan, Regression analysis and artificial intelligence approach for traffic accident prediction models in Turkey and selected some great provinces [M.S. thesis], Institute of Science and Technology, Kırıkkale University, 2007, (Turkish).

[19] A. P. Akgüngör and E. Doğan, "Artificial neural networks and genetic algorithm approach to accident prediction models own İstanbul metropolis," in Proceedings of the Modern Methods in Science Symposium, pp. 883-891, Eskişehir, Turkey, October 2008.

[20] U. Saray, M. Lüy, and E. Çam, "Wind speed estimation with artificial neural networks for Amasya," in Proceedings of the Electrical and Electronics Engineering Days, pp. 20-24, Ankara, Turkey, September 2011, (Turkish).

[21] M. Luy and U. Saray, "Wind speed estimation for missing wind data with three different backpropagation algorithms," Energy Education Science and Technology Part A: Energy Science and Research, vol. 30, no. 1, pp. 45-54, 2012. 


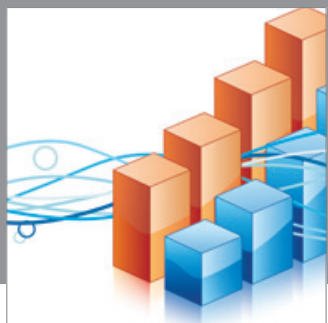

Advances in

Operations Research

mansans

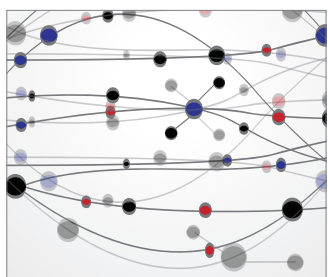

The Scientific World Journal
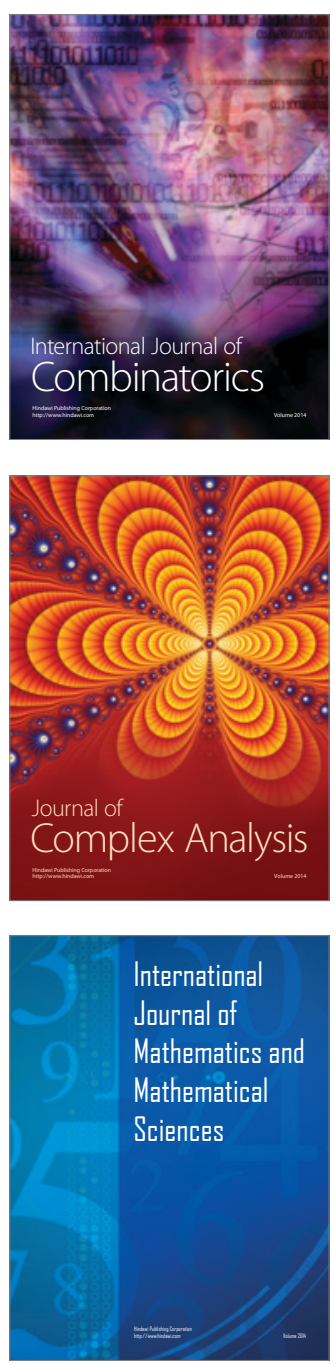
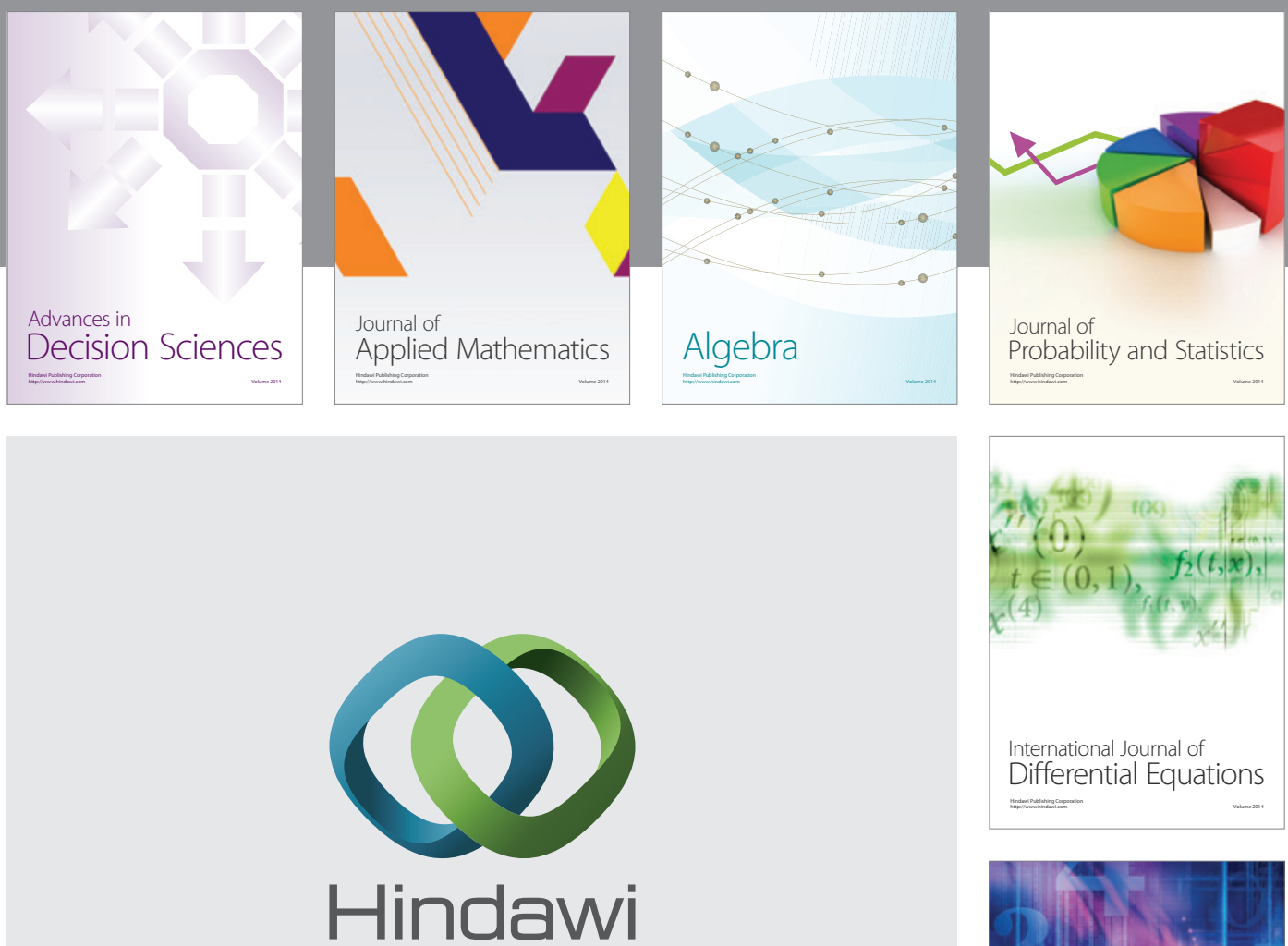

Submit your manuscripts at http://www.hindawi.com
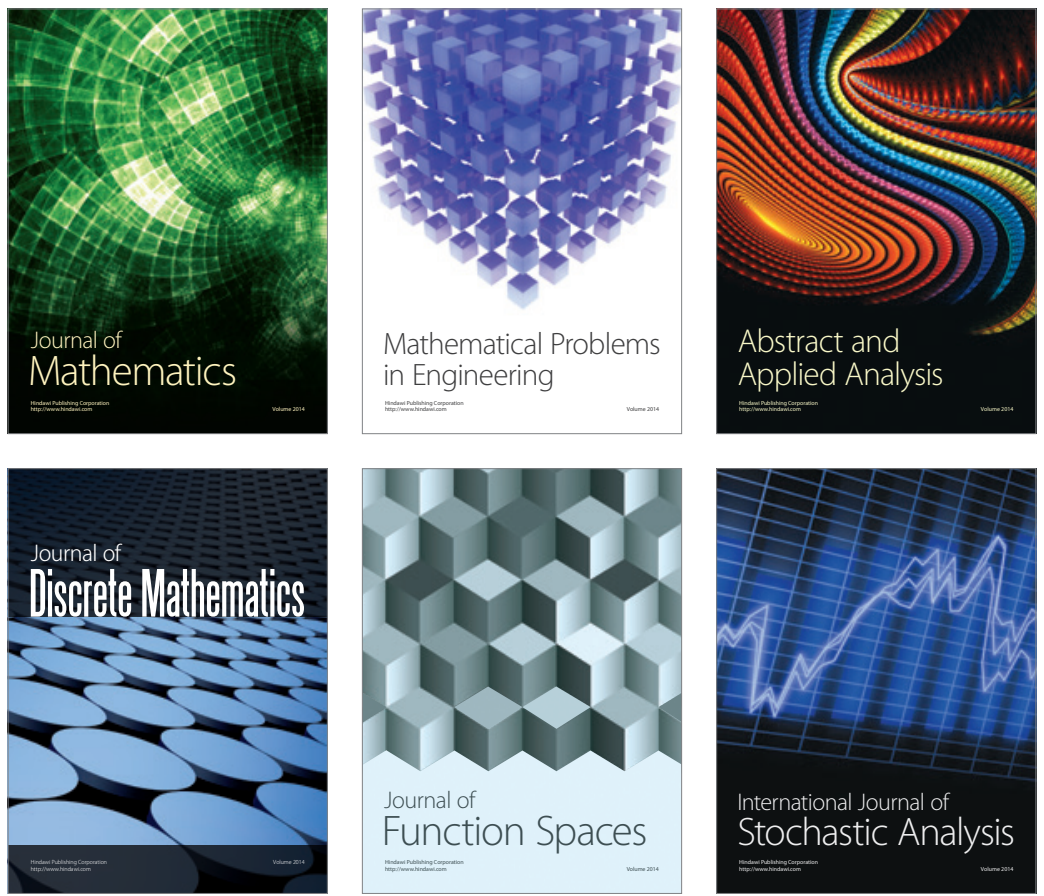

Journal of

Function Spaces

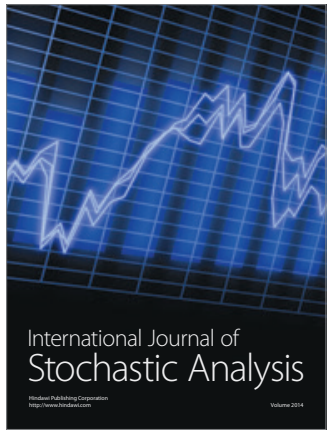

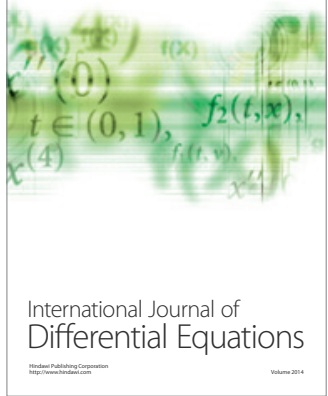
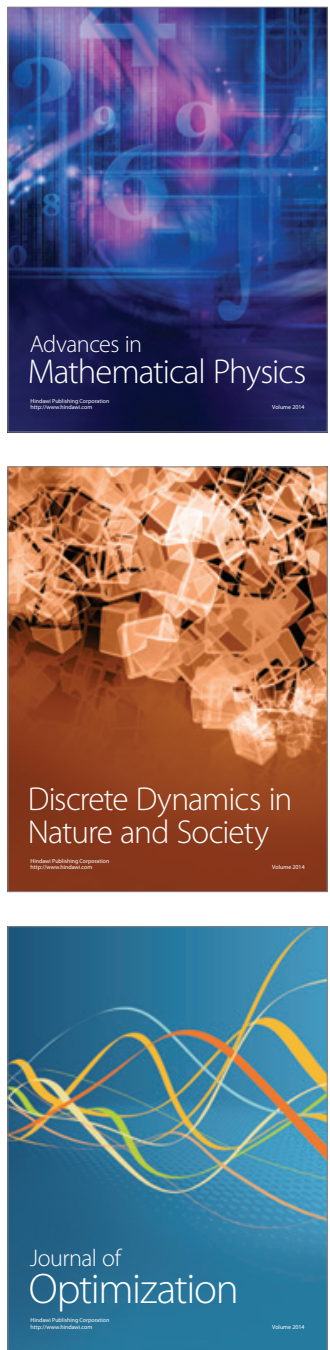